\title{
MAINTENANCE PERFORMANCE METRICS FOR MANUFACTURING INDUSTRY
}

\author{
Jitendra Kumar ${ }^{1}$, V.K. Soni ${ }^{2}$, Geeta Agnihotri ${ }^{3}$ \\ ${ }^{1}$ PhD Scholar, Dept. of Mechanical Engineering, MANIT, Bhopal, jitendra.me@gmail.com \\ ${ }^{2}$ Asst.Professor, Dept. of Mechanical Engineering, MANIT, Bhopal,soni_vk@rediffmail.com \\ ${ }^{3}$ Professor, Dept. of Mechanical Engineering, MANIT, Bhopal,dr.gagnihotri@gmail.com
}

\begin{abstract}
The purpose of this paper is to demonstrate various maintenance performance indicators (MPIs) within the perspective of maintenance metrics conducted by the managerial personnel for achieving the specified production target. In this paper, a conceptual framework has been developed, that provides guideline for choosing maintenance performance metrics for a typical manufacturing industry. It seeks to align maintenance objective with the performance indicators and provides a link between the two. Operations and maintenance of manufacturing system are of great economic importance. The review of literature on maintenance performance indicators and their measurement has been summarized under the five categories of metrics; functional metrics, equipment performance metrics, maintenance process metrics, periodicity metrics and OEE metrics. The review indicates that quantitative metrics for measuring maintenance performance are lacking. To address this gap, maintenance performance metrics has been proposed.
\end{abstract}

Keywords: Maintenance performance indicators, Performance metrics, Reactive Maintenance, Periodic maintenance, OEE

\section{INTRODUCTION}

Effective maintenance is critical to many operations. It extends equipment life, improves equipment availability and retains equipment in proper condition without delay of production schedules. The Maintenance Engineering Society of Australia (MESA) indicates that maintenance is about achieving the required asset capabilities within an economic or business context (MESA, 1995). They define maintenance as the engineering decision and associated actions, necessary and sufficient for optimization of specified equipment 'capability'. The term "capability" indicates the ability to perform a specified function within a range of performance levels that may relate to capacity, rate, quality and responsiveness (Tsang, 1998).

The four major factors (Karim, 2011) that cause defects in the product quality are human negligence, bad quality of raw material, machine that need maintenance and work procedure. After analysis it has been concluded that the machine maintenance from time to time is an important issue in quality control. To optimize and reduce defects \& occurring of machine damage, the plant managers should focus on the maintenance of machinery to ensure quality production at a satisfactory level.

A number of methods have been expressed by Antero Ollila and Markku (1999) like reactive maintenance, preventive maintenance, predictive maintenance and proactive maintenance. Reactive maintenance can be minimized by using methods like JIT (Just-In-Time), TQM (Total Quality Maintenance) to repair the machine $\&$ to reduce the defects in produced products. Further, for achieving zero defects, JIT and TQM method can be used in conjunction with the DPM (Downtime Due to Preventive Maintenance) methods. While the methods for preventive maintenance is a routine maintenance that has been set. Campbell (1995) proposed the implementation of two highly successful methods for the continuous improvement - RCM (Reliability centered Maintenance) and TPM (Total Productive Maintenance). Pintelon and Van Wassenhove (1992) have provided a maintenance management tool to evaluate maintenance performance. The tool consists of a control board and a set of reports to analyze certain ratios. This tool is applied in five different domains falling under the control of the maintenance manager: cost/budget, equipment performance, personnel performance, material management and work order control.

The outline of this article is as follows. Section 2 treats the possibility of performance metrics in achieving higher improvement. Section 3 gives an overview of the maintenance performance metrics and explains the importance of metrics. Section 4 describes the different maintenance performance metrics including functional metrics, equipment performance metrics, maintenance process metrics, periodicity metrics and 
OEE metrics. Conclusion and future research scope are formulated in section 5 .

\section{PERFORMANCE METRICS}

Performance metric is the fundamental instrument of the management which provides essential link between strategies, execution and ultimate value creation. Performance metric is a standard definition of a measurable quantity that indicates some aspect of performance and it is often viewed as being part of the infrastructure or environment in which manufacturing operation must operate. In other words a metric is nothing more than a standard measure to assess the performance in a particular area. Manufacturing and management consultant Oliver Wight almost 40 years ago offered the often repeated maxim, "you get what you inspect, not what you expect". All type of firms, activity, and worker needs metrics to evaluate fundamental activities of measuring, educating, and directing the gap for improvement. For the continuous improvement of plant, it is very essential to evaluate the present status of maintenance performance with respect to the fundamental, strategic and maintenance objectives defined by the corporate, plant and maintenance management. While making maintenance objectives, performance indicators and key performance indicators can be defined (Liyange, 2003) in the manner of either measure past or predict future performance. Operational performance indicators related to the maintenance are referred to as maintenance performance indicators (MPIs). MPIs are evaluated against goals coupled with the objectives by the company and the plant managers, respectively. Familiar maintenance metrics can be developed for measuring performance along the dimension of maintenance function, process, and equipment at the plant level maintenance activities which is untouched by the researcher.

\section{MAINTENANCE PERFORMANCE METRICS}

The European standard for maintenance key performance indicators (EN: 15341, 2007) provides three main categories of indicators namely economic indicators, technical indicators and organizational indicators. A hierarchical manner of key figures of industrial maintenance has been developed by Komonen (2002) like external, internal and intermediate objective variable including the business-oriented indicators.

The managerial aim of indicators is to guide plant operations and maintenance performance specifically. The different category of measure shows different areas of interest in maintenance performance in both literature and practice. The importance of maintenance performance measurements have extensively been discussed by many authors (Arts 1998; Tsang 1999; Visser 2003; Weber 2006; Parida 2007). Maintenance managers require performance information to monitor and control maintenance processes and results, which provide indication towards improvement. The measure of maintenance effectiveness is defined in terms of maintenance performance indicators (MPIs) for the plant. While, metrics are needed to evaluate the effectiveness of maintenance strategies and decisions regarding designing a new maintenance policy or redesigning an existing one. Such metrics should be simple to use to facilitate their application in today's changeable and reconfigurable manufacturing environment (wiendahl, 2007). In other words, there should be a strong dependency between maintenance performance metrics (MPMs) and the MPIs. Based on data analysis, this dependency should be reflected in a strong correlation between the MPMs and MPIs. Parida and Kumar (2006) identified the various issues and challenges associated with development and implementation of a maintenance performance measurement (MPM) system. The study finds that for successful implementation of MPM, all employees should be involved and all relevant issues need to be considered.

A huge numbers of indicators are used in the industrial maintenance but literature does not provide any methodology for selection of key performance indicators and usually it has been derived by the need and experience felt by the industry to industry. The similar type of indicators can be grouped within a performance metrics which can evaluate the performance of maintenance and such type of metrics is a great challenge for the researcher. In consequence a similar attempt has been made to develop maintenance performance metrics in the next section.

\section{DEVELOPING A BASIS OF MAINTENANCE PERFORMANCE METRICS}

As explained in previous section it is necessary to identify the needs of advance in order to maintain the normal functioning of production systems. Further the analysis of maintenance function is needed to implement better maintenance policy. For the same the performance of maintenance must be analyzed through performance indicators. The similar type of indicators can be grouped within a metrics for measuring maintenance performance according to the maintenance function. Moya (2004) developed a system composed of indicators to control the setting up predictive maintenance programs which should facilitate the early detection of anomalies which can appear during setting up to avoid the failure of maintenance program. The procedure for detailed metrics development is shown as follows:

(A). Metrics Collection and Definition: A comprehensive list of maintenance performance indicators is put together through extensive literature review including web based information sources. Each indicator is defined within their metric so that it's meaning and measures are clearly understood.

(B). Metrics Evaluation and Categorization: Each metric is evaluated based on its characteristics and maintenance work relevant to it, such as maintenance objective, strategies, process, and maintenance cost is involved. 
(C). Relevancy and Repetition Check: Each category is reviewed to ensure that all the metrics are relevant. Redundant ones are eliminated.

\subsection{FUNCTIONAL METRICS}

To ensure that plant operates at the required condition while meeting its production targets at an optimal cost, maintenance management has to make conscious decisions regarding the maintenance objective and strategies that need to be pursued. It is evident that (Kelly 1989; MESA 1995; Tsang 1999; Visser 2003), maintenance objectives are related to attainment of production target (through high equipment availability) at required quality within the constraints of the system condition and safety, utilizing optimum available maintenance resources so that the plant achieves its design life, the safety standard are met, the energy use and raw material consumption are optimized among the other factors (Dekker, 1996).

Maintenance objective has been summarized under the following five headings (as shown in Fig. 1): ensuring the functionality of plant so that plant achieves its design life within the environmental safety and cost effectiveness with effective use of resources. It is assumed that the maintenance objectives pursued at a given plant influences the kind of performance metrics or indicators used.

Once the maintenance objectives are outlined, maintenance strategy formulation is necessary to decide which type of maintenance needs to be done, when to do it and how often it can be done. According to Pintelon (2006) maintenance decision making can be broadly explained in terms of maintenance action, maintenance policies and maintenance concepts. Maintenance policies are the rules or set of rules describing the triggering mechanism for the different maintenance actions. Example of these policies are Failure based maintenance (FBM), use based or time based maintenance (UBM/TBM), condition based maintenance (CBM), design out maintenance (DOM) (Madu, 2000; Pintelon, 2002; savsar, 2006).

When maintenance objectives and strategies have been established, the success of functional metrics is dependent on the maintenance work management cycle, as outlined by Campbell (1995), consists of work identification, planning, scheduling, execution and closing the job. At the heart of the maintenance, functions are work planning and scheduling, which defines what gets done and when.

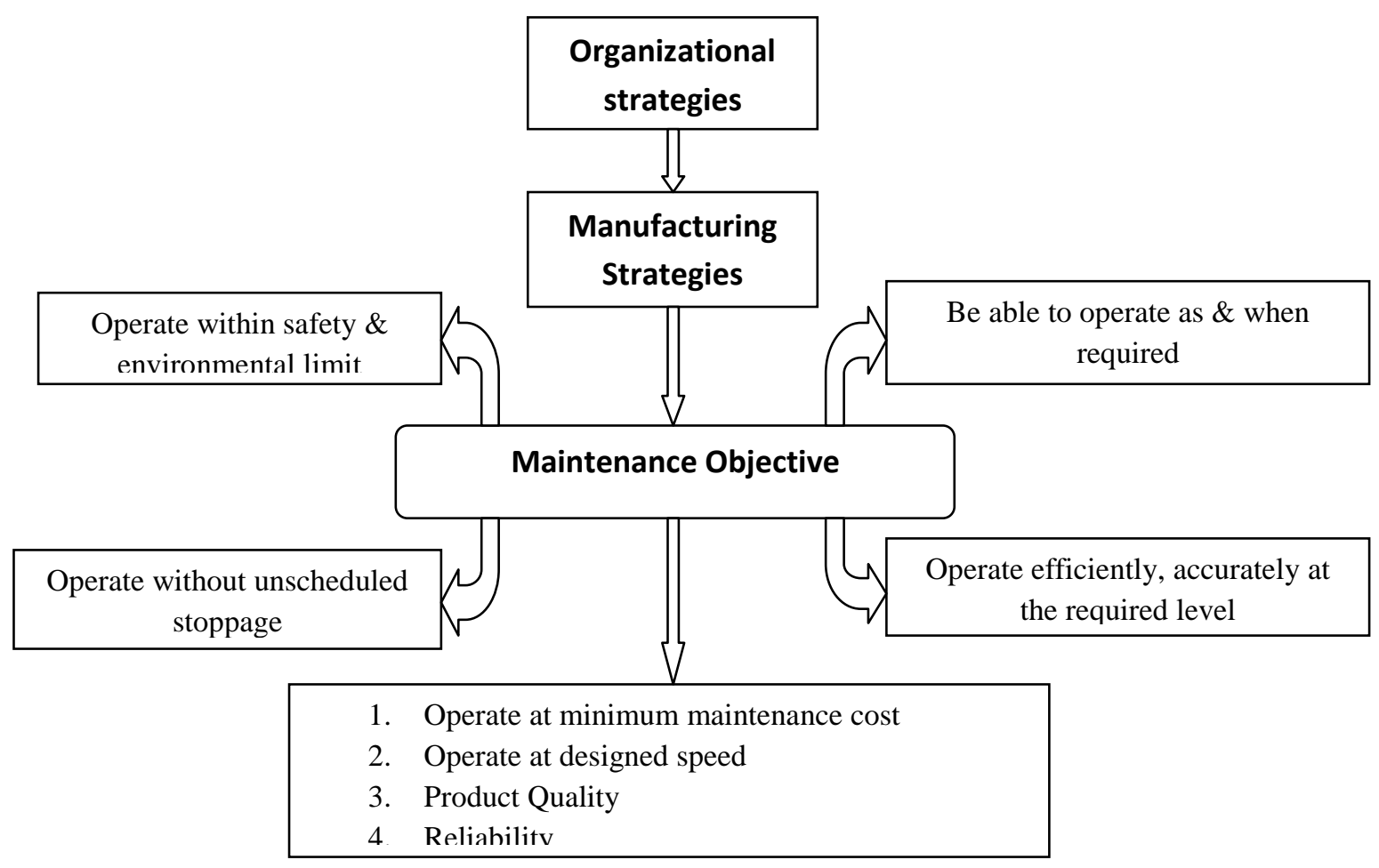

Fig. 1 Maintenance Objective for Maintenance Department 


\subsection{EQUIPMENT PERFORMANCE METRICS}

The role of the equipment condition in controlling quality and quantity is well known in the manufacturing industry (Daya, 1995). Equipment must be maintained in top operating conditions through adequate maintenance activities. From the analysis of the manufacturing and maintenance environment, it was found that equipment breakdown is the most important cause of production disruption among other causes of disruptions (quality, feedstock, logistics etc). Saxena (2008) developed algorithmic performance metrics to plan maintenance in advance to reduce downtime and maximize availability. Ollila and Malmipuro (1999) observed that the equipment availability has a major impact on efficiency and quality of production. An integrated maintenance model using statistical process control for monitoring quality of product has been developed by Noorossana (2011) and found that the quality of product is synonymous to monitoring status of equipment and as the result an out-of-control signal would indicate deterioration of the equipment. Huang et al. (2006) considered a further extension using a preventive maintenance (PM) that either brings the system to the 'as good as new' condition or the system will fail immediately because of faulty maintenance. Equipment performance (Rosqvist et al., 2009) can be analyzed through proactivity of maintenance task of equipment (Preventive tasks and actions/Maintenance tasks), equipment reliability (Number of functional failures/Operational cycles of equipment) and equipment availability (Downtime/Operational period of equipment).

Planning of preventive maintenance of technical system is assessed by the RCM (Reliability centered maintenance) analysis and it is gaining a solid reputation for successful method (Selvik, 2011). The analysis of RCM includes all historical records such as the list of functionality significant items (FSIA), the failure mode and effect analysis (FMEA), case based reasoning (CBR) and the basic reliability data (Cheng et al., 2008).

\subsection{MAINTENANCE PROCESS METRICS}

Marquez (2006) have defined maintenance process as the series of action at different stages which need to follow. The maintenance Process include assessing the feasibility and effort required to fulfill the need of maintenance for system change and scoping the work accordingly; planning, designing and implementing the changes to the system and accompanying documentation; testing the amended system at the unit, system, integration, and acceptance levels; and transitioning the amended system into production with minimal disruption of normal production level. At large the assessment of maintenance process has two parts effective analysis and efficiency analysis. The first part helps to detect the most important problems and locate their potential solution. The second part identifies the suitable procedure. The researcher define eight phases to accomplish this comprehensive assessment as: (1) determination of current factory performance
(2) quality and downtime (3) effectiveness analysis of alternative solution (4) efficiency analysis of maintenance procedure (5) plan action (6) implementing action and gathering of data (7) monitoring action and processing data (8) adaption of plans.

Lam (2007) introduced a special monotone process applied to a replacement model in which the operating times of system from a non-increasing geometric process and consecutive repair times constitute a non-decreasing geometric process. Chen (2010) identified Geometric process modeling as a useful tool to study repairable deteriorating system in maintenance problems. While maintenance Error Decision Aid (MEDA) process was developed (Rankin, 2000) based on the philosophy that maintenance technician do not make errors on the purpose, that errors result from a series of related contributing factors, and that these factors are largely under management control and, therefore, can be changed. The process was tested by the employees of airline and one repair centre. Grall (2010) discussed maintenance policies for stochastically deteriorating systems which are subject to sudden change in their degradation processes. From a maintenance decision making point of view two condition based maintenance policies are considered and compared through a numerical example and show that the time distribution of the change of deterioration rate and the difference between the two possible deterioration rates strongly influence the choice of the best decision rule structure.

\subsubsection{PLANNED MAINTENANCE PROCESS}

Planned Maintenance has two loops: Planning, scheduling, Execution and Follow up make up the first loop while second loop consists of work identification and performance analysis elements. Planned maintenance process is measured by schedule compliance i.e. the percentage of work orders completed during the scheduled period before the late finish or required by date. World class maintenance should achieve more than $90 \%$ during execution. An integrated model developed by Daya (2002) for the joint determination of economic production quantity and preventive maintenance (PM) level for an imperfect process having a general deterioration distribution with increasing hazard rate.

\subsubsection{ASSET RELIABILITY PROCESS}

The analysis of typical asset could include costs of planning, research and development, production, operation, maintenance and disposal. So a life cycle cost analysis calculates the cost of an asset for its entire life span whereas reliability analysis such as failure rate cost of spares, repair times, and component costs. In many maintenance problems, it is convenient to assume that repairs are either equivalent or less beneficial than the replacement and the system are brought back into an as good as new state after each repair and for the same Kallen (2011) used to model the effect of imperfect maintenance through the use of superposition of renewal process. This model can be 
extensively used to determine an approximate probability distribution of the time between repairs. Failed component are not repaired until a predefined fraction of the total number has failed.

\subsection{PERIODICITY METRICS}

The planned maintenance process is targeted to achieve required performance asset performance. For the better periodic maintenance activities, must be a better planning and scheduling. As planning develops procedure for maintenance work while scheduling evaluates the availability of all resources required for maintenance work "due" in a specified time frame.

Maintenance strategy is a structured combination of two maintenance action (Dekker, 1996) corrective and preventive which describes the events (e.g. failure, machine condition, etc.) and the type of action they trigger (i.e. inspection, repair, maintenance or replacement). Corrective maintenance which includes all actions performed as a result of a failure to restore an item to a specified working condition, while preventive maintenance includes all actions performed on operating equipment to restore them to a better condition.

Meselhy (2010) introduced two independent source of periodicity due to maintenance programs; the failure repair and pre-planned Preventive maintenance. Therefore, for the given maintenance policy parameter repair level (RL), periodicity extent expressed by the level of PM (PMLi), preventive maintenance frequency (PMFi) and the machine failure rate $\mathrm{E}$ $(\lambda)$, the total system periodicity can be expressed as:

$$
\text { Periodicity }=\frac{E(\lambda)}{\left(\frac{2}{R L}\right)-1}+\sum_{i=1}^{n} \frac{P F_{i}}{\left(\frac{2}{P M L_{i}}\right)-1}
$$

The above calculated periodicity is a measure of the relative ability of the maintenance strategy to resets the machine's functionality.

We may conclude that equipment performance are measured on a shorter time interval (daily and weekly basis), probably to facilitate quicker corrective actions. Rosqvist et al. (2009) discussed Periodic preventive maintenance task related to preventive maintenance strategies which are either conditionbased (periodic functional testing, periodic inspection, condition monitoring, operation supervision) or predetermined (periodic restoration, periodic servicing, Modification work).

\subsection{OEE METRICS}

The total productive maintenance (TPM) concept launched by Nakajima (1988) provides a quantitative metric called Overall Equipment Effectiveness (OEE) for measuring productivity of manufacturing equipments. OEE metric and its variants came out as the most popular equipment performance indicator capable of measuring different production losses, of which maintenance related losses are important. The important maintenance indicators in the OEE have shown in the fig 2.

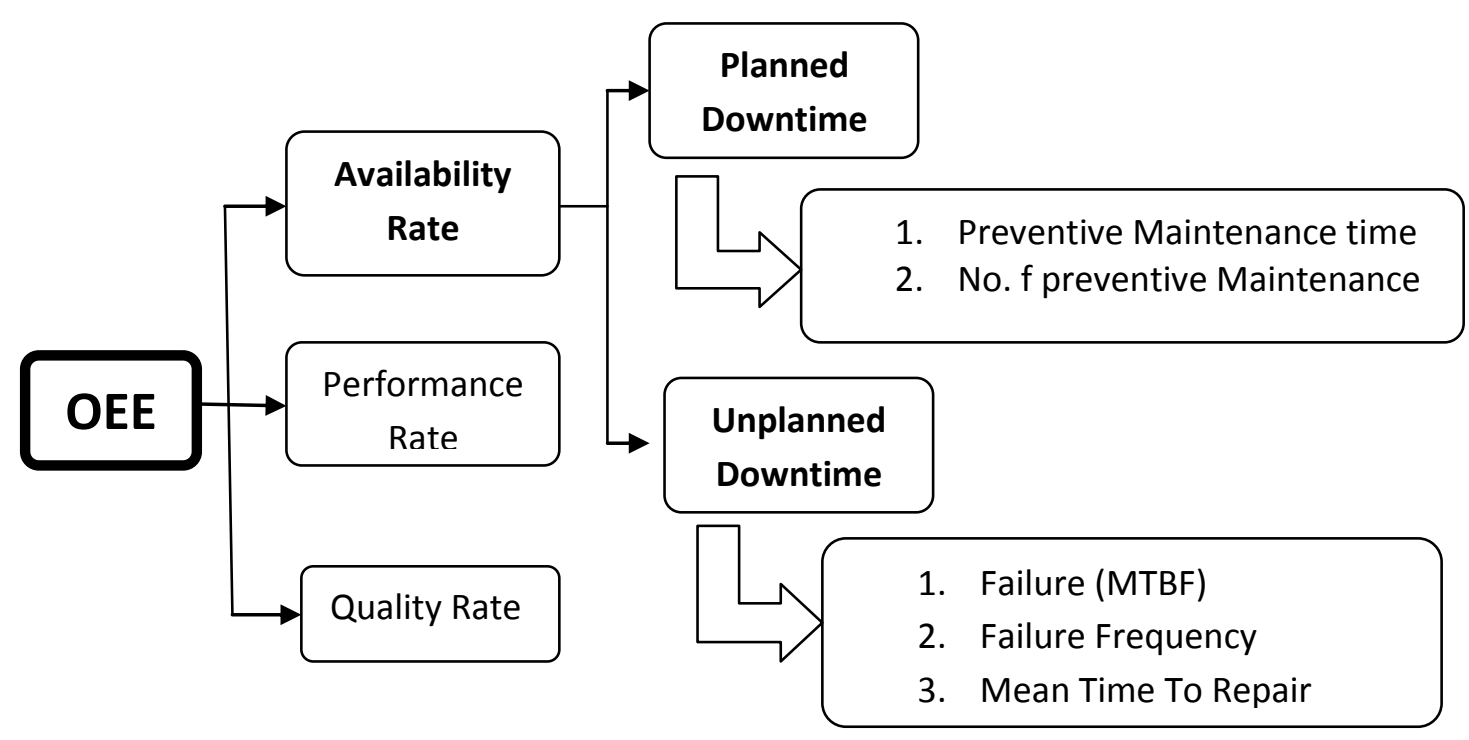

Fig. 2 Maintenance Indicator in the OEE Metrics 
The OEE concept has become increasingly popular and has been widely used as a quantitative tool essential for measurement equipments' performance in industries (Huang 2003; Muchiri 2008).

$$
\begin{gathered}
\text { OEE }=\text { Availability }(\mathrm{A}) \mathrm{X} \text { Performance }(\mathrm{P}) \times \text { Quality }(\mathrm{Q}) \\
\mathrm{A}=\frac{\text { calender time }- \text { Downtime }}{\text { calender time }} \times 100 \\
\mathrm{P}=\frac{\text { Processed amount }}{\text { operating time }} \times 100 \\
\mathrm{Q}=\frac{\text { processed amount }- \text { Defective amount }}{\text { processed amount }} \times 100
\end{gathered}
$$

This metric has become widely accepted as a quantitative tool essential for measurement of productivity in manufacturing operations (Samuel et al., 2002). One of the most critical success factors influencing survival, profitability, and competitive advantage of manufacturing organization is to select proper maintenance policy. OEE is mostly used in one of the policies, i.e. total productive maintenance and it helps in decision making (Shahin, 2011) to improve the overall performance of organizations.

Using OEE metrics and establishing a disciplined reporting system help an organization to focus on the parameters critical to its success. Analyzing OEE categories can reveal the greatest limits to success.

\section{CONCLUSIONS}

In this paper, a conceptual framework has been developed that provide the overview of maintenance performance metrics aligning various maintenance performance indicators according to the maintenance objective of the plant. The maintenance performance metrics are summarized under the five categories: functional metrics, equipment performance metrics, maintenance process metrics, periodicity metrics and OEE metrics. The aim is to ensure that the key indicators must be measured within the metrics to evaluate the maintenance performance.

This research demonstrates that the performance indicators can be grouped within a metric so that the maintenance performance analysis will be easy to review. Further research work is recommended on the maintenance diagnostic metrics and maintenance cost metrics which plays key role in the operation and maintenance department to evaluate the performance and further improvement. Since the availability of maintenance metrics may not necessarily guarantee low maintenance cost, hence a maintenance cost metrics may be derived for the low cost repair, replacement and maintenance in practice.

\section{REFERENCES}

[1] Arts, R.H.P.M., Knapp, G.M., Mann, L. (1998), "Some aspects of measuring maintenance performance in process industry", Journal of Quality in Maintenance Engineering, 4 (1), 6-11.

[2] Campbell J. D., Uptime. (1995), "Strategies in excellence in maintenance management", Portland: Productivity Press; 1995.

[3] Chen J. et al. (2010), "Bayesian computation for geometric process in maintenance problem", Mathematics and computers in simulation, 81:771-781.

[4] Cheng et al. (2008), "A framework for intelligent reliability centered maintenance analysis", Reliability engineering and system safety 93:784-792.

[5] Christer AH, Wang W, Sharp JM., (1997), "A state space condition monitoring model for furnace erosion prediction and replacement", European Journal of Operation Research, 101:1-14.

[6] Daya, B., Duffuaa, S., (1995), "Maintenance and quality: The missing link", Journal of Quality in Maintenance Engineering, 1 (1), 20-26.

[7] Dekker, R., (1996), "Application of maintenance optimization models: a review and analysis", Reliability Engineering and System Safety, 51, 229-240.

[8] EN: 15341, (2007), "Maintenance Key Performance Indicators", European Committee for Standardization (CEN), Brussels, Belgium.

[9] Grall, A., et al. (2010) "assessment of a maintenance model for a multi-deteriorating mode system", Reliability Engineering and system safety, 95:12441254.

[10] Kallen, MJ., (2011) "Modeling imperfect maintenance and the reliability of complex system using superposed renewal processes", Reliability Engineering and system safety, 96: 636-641.

[11] Karim, K. and Talib, A., (2011), "total productive maintenance application to reduce Defects of product", Journal of applied science research, 7(1):11-17.

[12] Kelly, A., 1989. Maintenance and its Management. Conference communication London.

[13] Komonen, K., (2002) "A cost model of industrial maintenance for profitability analysis and benchmarking", International Journal of Production Economics, 79, 15-31.

[14] Lam, Y., (1991) "An optimal repairable replacement model for deteriorating systems", J. Appl. Prob., 28: 843-851.

[15] Lam, Y., (2007) "A geometric process maintenance model with preventive repair", European Journal of Operational Research, 182:806-819.

[16] Liyange JP, Kumar U., (2003) "Towards a value based view on operations and maintenance performance management" Journal of Quality \& Maintenance Engineering, (9): 333-350. 
[17] Lupinucci M, Perej J, Davila G., (2000) "Improving sheet metal quality and product throughput with Bently's Machinery Management system", orbit. Bently Nevada; 21 (3), 37-41.

[18] Madu, C., (2000) "Competing through maintenance strategies", International Journal of Quality \& Reliability Management, 17 (9), 937-948.

[19] Marquez A.C., and Gupta, J.N.D., (2006) "contemporary maintenance management: process, framework and supporting pillars" Omega 34:313-326.

[20] Meselhy, K.T., et al. (2010) "A periodicity metric for assessing maintenance strategies", CIRP Journal of Manufacturing Science and Technology. (3), 135-141.

[21] MESA, (1995) "Maintenance Engineering Society of Australia capability Assurance: A Generic Model of Maintenance", Maintenance Engineering Society of Australia (MESA), Australia.

[22] Muchiri, P.N., Pintelon, L., (2008), "Performance measurement using overall equipment effectiveness (OEE): Literature review and practical application", International Journal of Production Research, 46 (13), $3517-3535$.

[23] Nakajima, S., (1988), "Introduction to TPM: Total Productive Maintenance", Productivity Press, Cambridge, MA.

[24] Ollila, A., M. dan Malmipuro, (1999), "Maintenance Has a Role in Quality", The TQM Magazine, 11(1): 17- 22.

[25] Pintelon LM, Van Wassenhove (1992) "A maintenance management tool”, Omega; 18(1):59-70.

[26] Parida, A., Chattopadhyay, G., (2007), "Development of a multi-criteria hierarchical framework for maintenance performance measurement (MPM)", Journal of Quality in Maintenance Engineering, 13 (3), 241-258.

[27] Pintelon, L., VanPuyvelde, F., (2006), "Maintenance Decision Making", Leuven, Belgium, Acco.

[28] Rosqvist, T. et al., (2009) "Value-driven maintenance planning for a production plant", Reliability Engineering and system safety 94: 97-110.

[29] Savsar, M., (2006), "Effects of maintenance policies on the productivity of flexible manufacturing cells", Omega International Journal of management Science, 34, 274282.

[30] Shahin, A., (2011), "Developing Decision making grid for maintenance policy making based on estimated range of OEE", Modern applied science, 5 (6)

[31] Tsang, A.H.C., (1998), "A strategic approach to managing maintenance performance", Journal of Quality in Maintenance Engineering, 4 (2), 87-94 (8).

[32] Tsang, A.H.C., (1999), "Measuring maintenance performance: a holistic approach", International Journal of Operations and Production management 19 (7), 691715.

[33] Tsang, A.H.C., (1998), "A strategic approach to managing maintenance performance", Journal of Quality in Maintenance Engineering, 4 (2), 87-94 (8).
[34] Villar JM, Masson LO, Gomes JA., (2003) "Proactive maintenance - A successful history", orbit, Bently Nevada; 21(3):33-41.

[35] Visser, J.K., Pretorious, M.W., (2003), "The development of a performance measurement system for maintenance, SA Journal of Industrial Engineering, 14 (1), 83-97.

[36] Wiendahl, H.P., et al. (2007), "changeable Manufacturing- Classification, design and operation", CIRP Annals-Manufacturing Technology, 56 (2), 783809.

[37] Weber, A., Thomas, R., (2006), "Key Performance Indicators: Measuring \& Managing the Maintenance Function", Ivara Corporation.

\section{BIOGRAPHIES:}

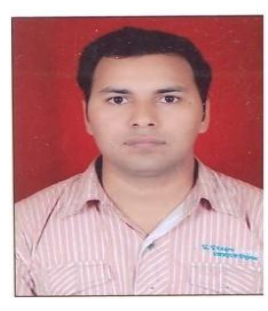

Jitendra Kumar holds a Bachelor's Degree in Mechanical Engineering and M. Tech in Industrial Design from LNCT, Bhopal. Presently, he is pursuing $\mathrm{PhD}$ in the Dept. of Mechanical Engineering, M.A.National Institute of Technology, Bhopal. His main research area is Industrial Engineering \& Management. Jitendra Kumar is the corresponding author and can be contacted at: jitendra.me@gmail.com 